\title{
Centrifugal Compressor Design for a Gasoline Engine Turbocharger
}

\author{
Qingbin Li ${ }^{*}$, Hanqin Yang, Liaoping Hu, Guangqing He, Lin Liu, Tao Feng
}

Hunan Tyen Machinery Co., Ltd, Hengyang, P. R. China

Email address:

liqingbin1985@163.com (Qingbin Li)

${ }^{*}$ Corresponding author

\section{To cite this article:}

Qingbin Li, Hanqin Yang, Liaoping Hu, Guangqing He, Lin Liu, Tao Feng. Centrifugal Compressor Design for a Gasoline Engine Turbocharger. International Journal of Fluid Mechanics \& Thermal Sciences. Vol. 6, No. 1, 2020, pp. 27-35.

doi: $10.11648 /$ j.ijfmts.20200601.14

Received: February 10, 2020; Accepted: February 25, 2020; Published: March 6, 2020

\begin{abstract}
With increasing challenges in both fuel consumption and emission, the turbochargers have played a very important role for gasoline engines. Turbochargers can increase engine power density, reduce physical dimensions and reduce engine weight. Most of the turbochargers have a rotor system including a centrifugal compressor and a turbo turbine. Centrifugal compressors is a turbomachine which increases the gas pressure with the help of a turbine. Centrifugal compressors dominate the turbocharger applications. Centrifugal compressor performances are very critical for turbocharger performance. Gasoline engines need compressor not only to have high efficiency at whole operating range but also have a wide operating range. This paper discussed a centrifugal compressor design for gasoline engine turbocharger. The modern compressor design process developed recently was used for this new compressor design. The performance of the new design was compared with original compressor in CFD (Computational Fluid Dynamics) analysis, gas stand test and engine test. It demonstrated that the newly developed compressor has better performance and also meet the engine operating needs from both numerical analysis and test. The new centrifugal compressor development is successful.
\end{abstract}

Keywords: Turbochargers, CFD, Centrifugal Compressors, Gas Stand Tests

\section{Introduction}

The development trend of the gasoline engine is toward small size, high efficiency and low emission. The turbochargers have become one of the ways to meet the needs of the new gasoline engine's fuel consumption and emission needs. Centrifugal compressor and radial turbine are the key components of the turbochargers. The new developments of the compressors and turbines are always the challenges of turbocharger manufacturers [1]. In a centrifugal compressor, the flow enters the compressor in axial direction and exits the wheel in the radial direction. The gas continuously enters the rotating wheel. The turbine mechanical power transfers to the compressor through a shaft. The gas static pressure and momentum increase inside of the wheel with the help of the wheel blades. The remaining kinetic energy is afterwards converted into static pressure in diffuser. The compressed gas is then either collected in a volute or transferred to a second compressor stage.

With the new challenges of the gasoline engines, centrifugal compressor design of the turbocharger is critical. In the past, gasoline engine manufacturers are focusing on the compressor high speed performances in order to have enough engine torque at high engine speeds. The new gasoline engines need compressors to have high-efficiency both in low speeds and high speeds. At engine low speeds, the compressor performance is very critical for engine fuel consumption and emission. As engine works at low speeds, it has less exhaust air to drive turbocharger turbine. Turbine provides less power to drive the compressor. With the requirements of fuel consumption and emission at low engine speeds, it needs a compressor to provide more air for gasoline engine. At this situation, turbine and compressor efficiency are very important. This provides a challenge for compressor and turbine design. Many efforts have been made for compressor and turbine designs to improve the efficiency in both low compressor rotating speeds and high rotating 
speeds [1-23].

Turbochargers have been widely used in passenger vehicle engines. Gasoline engines are a larger portion of the passenger car. Turbochargers for gasoline engines have different requirements then diesel engines. Normally diesel engine turbochargers have higher pressure ratio than gasoline turbochargers. However, recently, the gasoline engine turbochargers have a trend to increase the pressure ratio. Nowadays, the pressure ratio of the conventional gasoline engine turbocharger at the rated point is about 2.5 which is lower than that of the diesel engine. But compared to the past the current gasoline engine pressure ratio has been increased a lot. In the past, the maximum pressure ratio of the gasoline engine is about 1.8. After the increase of the pressure ratio, the peak torque point of the external characteristic of the engine lugline is close to the surge boundary of the compressor. The old compressor can not be directly to use. The old compressors need to improve the stability of the compressor. In addition, the operating range of the engine speed of the gasoline engine is become wider compared with in the past. The rated torque point is 6000rpm while the idle speed for most current gasoline engines is only 750rpm.

Because the inlet air flow of the turbocharger compressor is directly proportional to the engine speed, gasoline engines require a wider compressor flow range to meet the wider range of engine speeds. Compressors generally have narrower operating ranges as the pressure ratio and rotating speed increases. In addition to meeting the high altitude needs, the external characteristic of the compressor lugline shifts to the upper right. This characteristics easily causes the external characteristic to be outside of the compressor characteristic curve. The demand for steady-state flow range and efficiency leads to small compressor wheel. However, the good altitude performance needs a larger compressor wheel. The compressor design becomes more challenges because the compressor needs higher efficiency and wide operating range with the increase of the EGR rate of gasoline engines, the miniaturization of engines, the demands of the engine control, and the stability of the compressor.

A centrifugal compressor has three main components: compressor wheel, diffuser and volute. It is very important to design a high efficiency wheel with wide operating range. The aerodynamic performance of the compressor wheel affects the diffuser and volute performance. Turbomachinery industry is increasingly interested in using optimization procedures that enable enhanced compressor efficiency and widen operating ranges [2-9]. Compressor design normally starts with a meanline program at each individual operating point on a map. Then throughflow calculation is performed. Finally the compressor wheel, diffuser and volute are designed. During the compressor development, designers always compromise between a peak attainable efficiency and an overall operating range.

The development of computer technologies and advancements in turbomachinery technology have made the centrifugal compressor design possible and easier than ever before. The compressor design not only needs to focus on the engine peak torque point performance, but also need to optimize off-design performance. Recently, multi-discipline optimizations have drawn more attention. Due to the complications of the engineering system and complications of multi- disciplines, compressor design is still very challenge. $\mathrm{Xu}$ and Amano [2-8] developed a design process to optimize the compressor design both in aerodynamics and structure reliability. Gonzalez et al. [10] recently developed a system for the integrated design optimization of gas turbine engines; postponing the setting of the interface constraints to a point facilitates better exploration of the available design space and better exploitation of the trade-offs between different disciplines and modules. Verstraete et al. [11] developed a multidisciplinary optimization system and used it to design a small radial compressor wheel.

\section{Compressor Design, Analysis and Tests}

This section discusses developments of a new centrifugal compressor for a $1.5 \mathrm{~L}$ direct-injection gasoline engine applications. The original turbocharger has eight full-blades for compressor wheel for the consideration of BPF noise. There is no splitter blade. The new compressor design requires the same number of blades and without splitter blade. It is necessary to further increase the engine medium and high speed power while maintaining the low speed performance as much as possible. The compressor wheel can be milled with five axes in-house with relatively low cost and shortest time. The increase engine power needs a better efficiency compressor with wide operating range. This study attempts to optimize the design of the existing centrifugal compressor wheel to improve the flow range and efficiency. The main optimizations were performed at the inlet flange, trailing edge shape, shroud and hub meridional design. CFD simulations and gas stand tests are used to verify the compressor design [24].

A recently developed method for turbomachinery design for aerodynamic and structure optimizations $[6,22-30]$ was used to fully optimize a centrifugal compressor design. The main focus of this study is in emphasizing the importance of the meridional shape and trailing edge loading related to a centrifugal compressor aerodynamic performance. During the study, the wheel blade angle changes with the percentage of the meridional distance being maintained the similar, while the meridional shape was changed. In this way, the blade loading near trailing edge reduces at shroud. The compressor efficiency improved. Design 1 is a newly proposed meridional shape with a vertical inlet and an exit with a clipped, smooth-curved shroud shape. Design 2 is the original meridional design with an inlet tip cut back and a flat discharge. CFD calculations and tests indicated that Design 1 had a relative higher efficiency and wider operating range. However, the calculations show that the surge flow does not change too much.

All calculations use commercial software NUMECA FINE / Turbo. The steady solver is used to solve the three- 
dimensional Reynolds Average N-S equations. The FINE/Turbo software package EURANUS solver uses the lattice center finite volume method for numerical calculations. The space matching uses a second-order central difference scheme with an artificial viscosity term. The calculation uses three-layer multi-grid combined with a variable time step and residual smoothing method for better convergence. The flow at wheel inlet is fully turbulent. The turbulence model uses the Spallart-Allmaras single equation turbulence model in current calculations. A CFD model of single channel of the compressor wheel, diffuser and a whole volute are used for calculation domain. The wheel and diffuser periodic boundary conditions are used to avoid to calculate the whole wheel. The use of a structural grid ensures the calculation quality and converge faster with less grids. The grids near the wall using very fine cells to make should the $\mathrm{y}^{+}$less than 1 . The height of the first layer of the wheel and the volute grids is $0.001 \mathrm{~mm}$. There are 13 grid nodes in the gap between the wheel shroud and casing. The number of wheel grids is about 1.3 millions in the domain of inlet, wheel and diffuser. The volute grid is 1.2 millions, as shown in Figure 1 below. The grid topology of the wheel and the volute in each compressor scheme are consistent, which ensures the credibility of the analysis results.

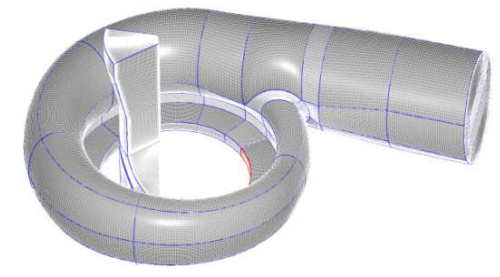

Figure 1. CFD mesh.

Boundary conditions such as absolute total pressure, absolute total temperature, and velocity vector direction are applied to the compressor inlet. Mass flow boundary conditions is used at the compressor outlet. The solid wall surface adopts the non-slip and adiabatic condition. The mass flux, momentum flux and energy flux passing through the solid wall surface are zero. To determine whether the calculations have converged, the following standards are usually used as a reference: the global residual is reduced by more than third orders of magnitude; the most important parameter of the convergence criterion is the inlet and outlet mass flow, whose relative error should be less than $0.02 \%$. For stage calculations, the converge results are assume the overall performance parameters i.e. efficiency, pressure ratio, torque, etc., variation less $0.01 \%$ of the mean value as the number of iteration steps increases.

The measurement of the compressor performance curves were completed on the turbocharger test bench. The speed measurement of the turbocharger on the test bench is displayed by a non-contact magnetoelectric sensor and displayed on a speed meter. The rotating speed measurement uncertainty is $0.2 \%$. The pressure sensor uncertainty is about 1.0 pa. Temperature measurements use platinum thermal resistance thermal couples with uncertainty of $0.2 \%$. The inlet flow of the compressor is measured using a double button wire flow meter. The temperature, pressure and speed measuring instruments on the test bench are calibrated and in the valid period of use. For obtaining a high accuracy measurement data, a measurement system analysis (MSA) was carried out on the test bench. The MSA analysis performed at three turbo flow points: low, medium, and high design speeds. The three test bench operators repeated the measurement three times for each speedline. The evaluation indices of the measurement system are shown in Table 1 below. Through data analysis. It is found that the measurement system is reliable and good to use. The measured SV\% values are less than $19 \%$, the number of distinguishable categories are all greater than 5, and the reliability of the measurement system is high, as shown in Table 1:

Table 1. Measurement system.

\begin{tabular}{lll}
\hline Measurement system evaluation & Variation (\% SV) & Categories \\
\hline Measurement system is in poor condition and must be improved & $>28 \%$ & $<5$ \\
Measurement system works, but there is still room for improvement & $14 \%-28 \%$ & $<-10$ \\
The measuring system is in good working condition & $<14 \%$ & $>10$ \\
\hline
\end{tabular}

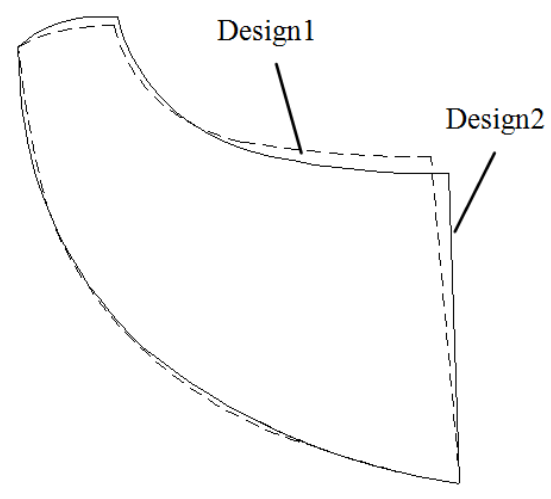

(a) Meridional view of the two designs.

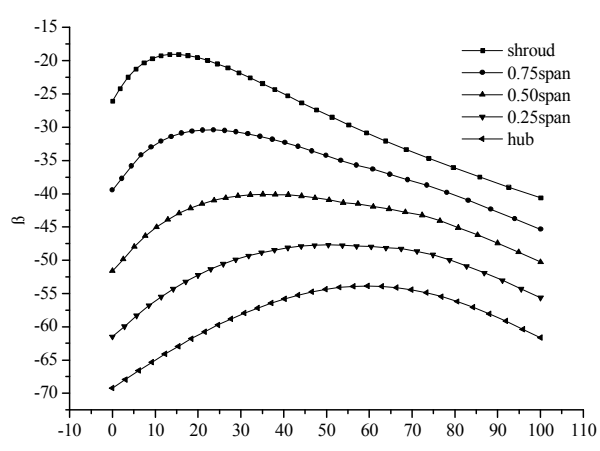

(b) Blade angle distributions along the meridional length.

Figure 2. Geometry of Design 1 and Design 2. 


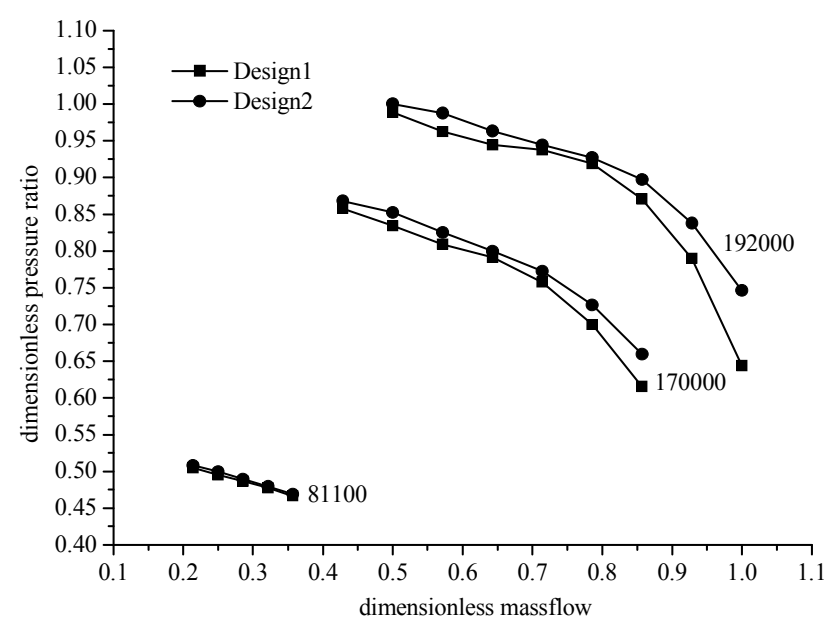

(a) Pressure ratio.

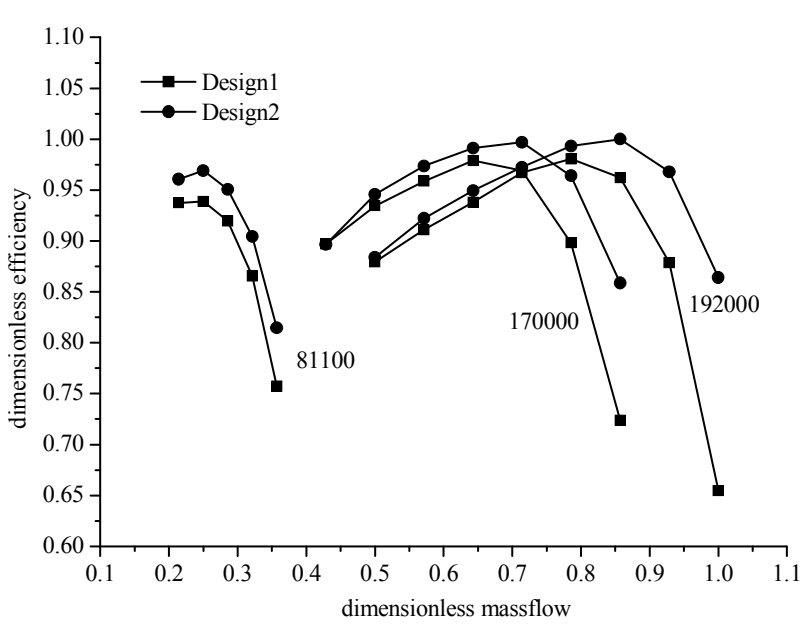

(b) Efficiency.

Figure 3. Comparison of compressor performance.

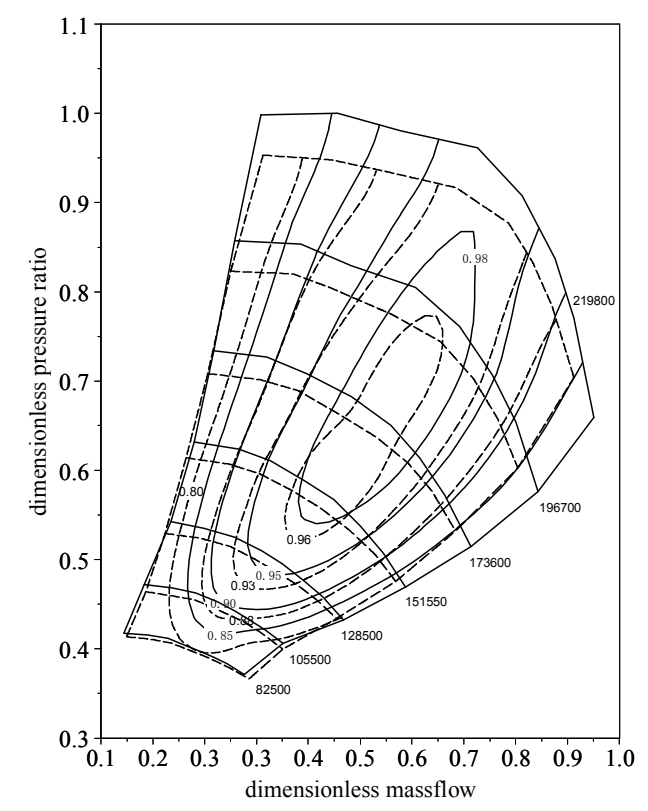

Figure 4. Comparison of compressor characteristics test.

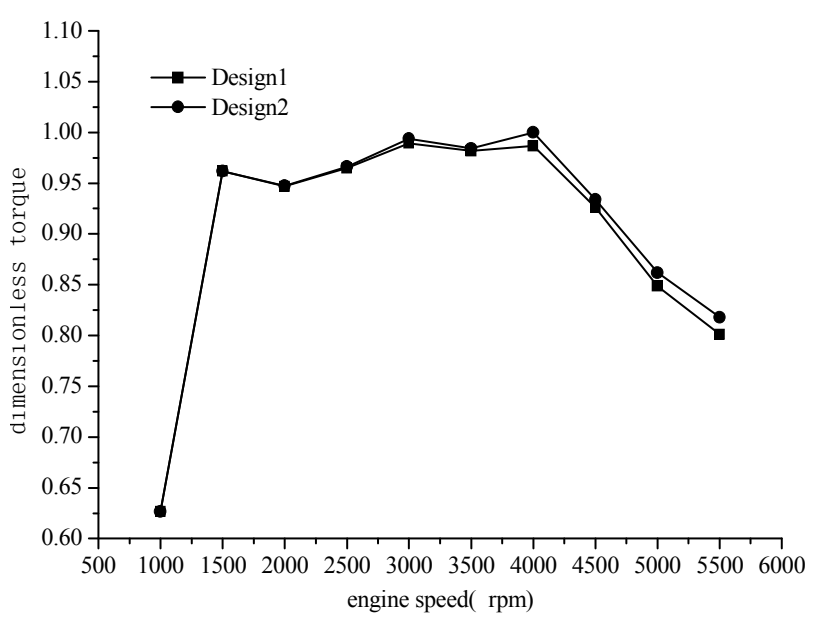

(a) Engine torque.

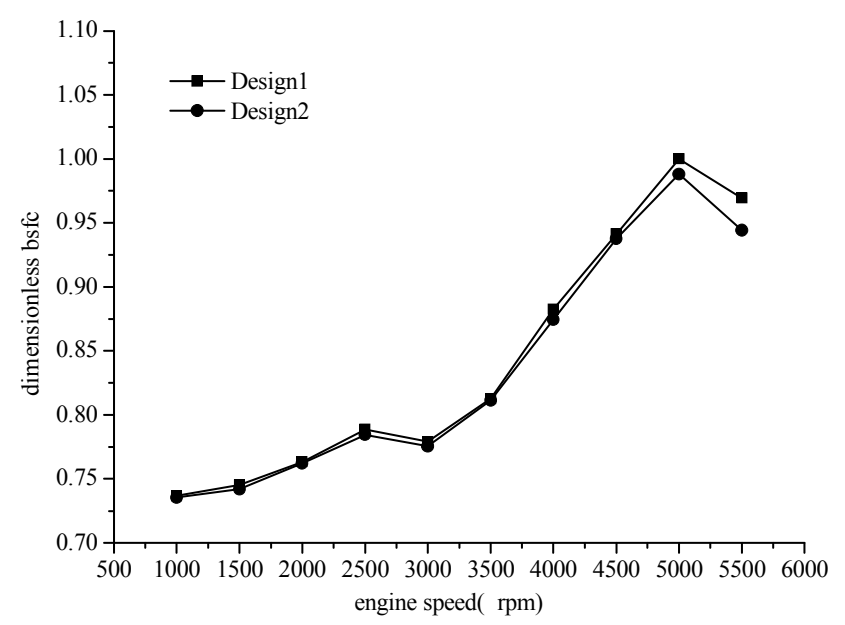

(b) Engine bsfc.

Figure 5. Engine bench test comparison.

\section{Results and Discussion}

In this study, based on the original wheel Design1, the original wheel good characteristics were maintained. The radial shape of the wheel such as the inlet and outlet trailing edges, shroud, and hub shapes were optimized to obtain the Design2, as shown in Figure 2 (a). The differences between Design 1 and Design2 are clearly seen from meridional point of view. The Design 1 wheel uses a backward-sloping leading edge and curved outlet design, the improvements were significant and there are very limited publications reporting this kind of designs. The aerodynamic load uniformity of the shroud and hub of the wheel were achieved and performance of the compressor stage is improved.

The calculation results of the two schemes are shown in Figure 3. Design2 had a relative higher efficiency and wider operating range. This is because the shroud section has a more general distribution of the blade loading. Also, both the shroud side and the hub side have a similar pressure raise along the meridional direction, which reduced the flow mixing loss between the shroud and the hub at the wheel exist. The design intention was to make a uniform 
distribution of the wheel exit static pressure. The analysis also indicates that, Design 2 has a higher pressure ratio compared with Design 1. Design 2 shows about a 10\% higher pressure ratio compared with Design 1. This is because Design 2 has a larger diameter at the exit shroud. The increase of the exit diameter raises the pressure ratio. The increase of the shroud wheel exit diameter also increases the overall flow capacity.

From the comparison results of the compressor test characteristics in Figure 4 can be seen that the test results are consistent with the CFD simulation results. The design 2 wheel pressure ratio and efficiency at medium and large flow rates are better than Design1 which verifies the feasibility of the simulations.

Figure 5 shows the comparisons of the external characteristics of on the engine bench tested. The torque of the medium and high-speed engines has been increased. Among them, the rated point engine torque has been increased by nearly $2 \%$, and the overall external characteristic fuel consumption has been reduced.

Because this design mainly improves the performance of medium and high speed, we selected the rated operating point of the engine for flow field analysis as shown in Figure 6 and Figure 7 for design 1 and design2. As can be seen from the static pressure distributions at the rated point in the figure below, Design1 has a large range of low-pressure zones at the leading edges of the $50 \%$ and $90 \%$ span wheel from inlets. There is a large acceleration in the compressor wheel on the suction surface of the blade. In addition, along the streamline direction, the static pressure increase of Design2 is more uniform than that of Design1. The suction surface of Design 1 has more lower static pressure value than its pressure surface, after the flow leaving the blade outlet, due to the large pressure difference, a large mixing loss is occurred.

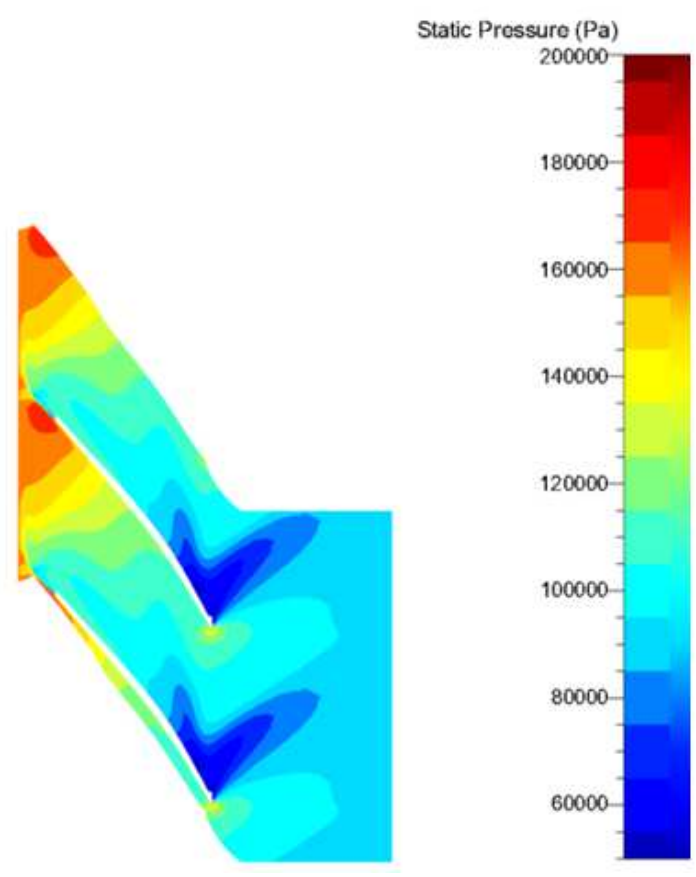

(a) $90 \%$ span.
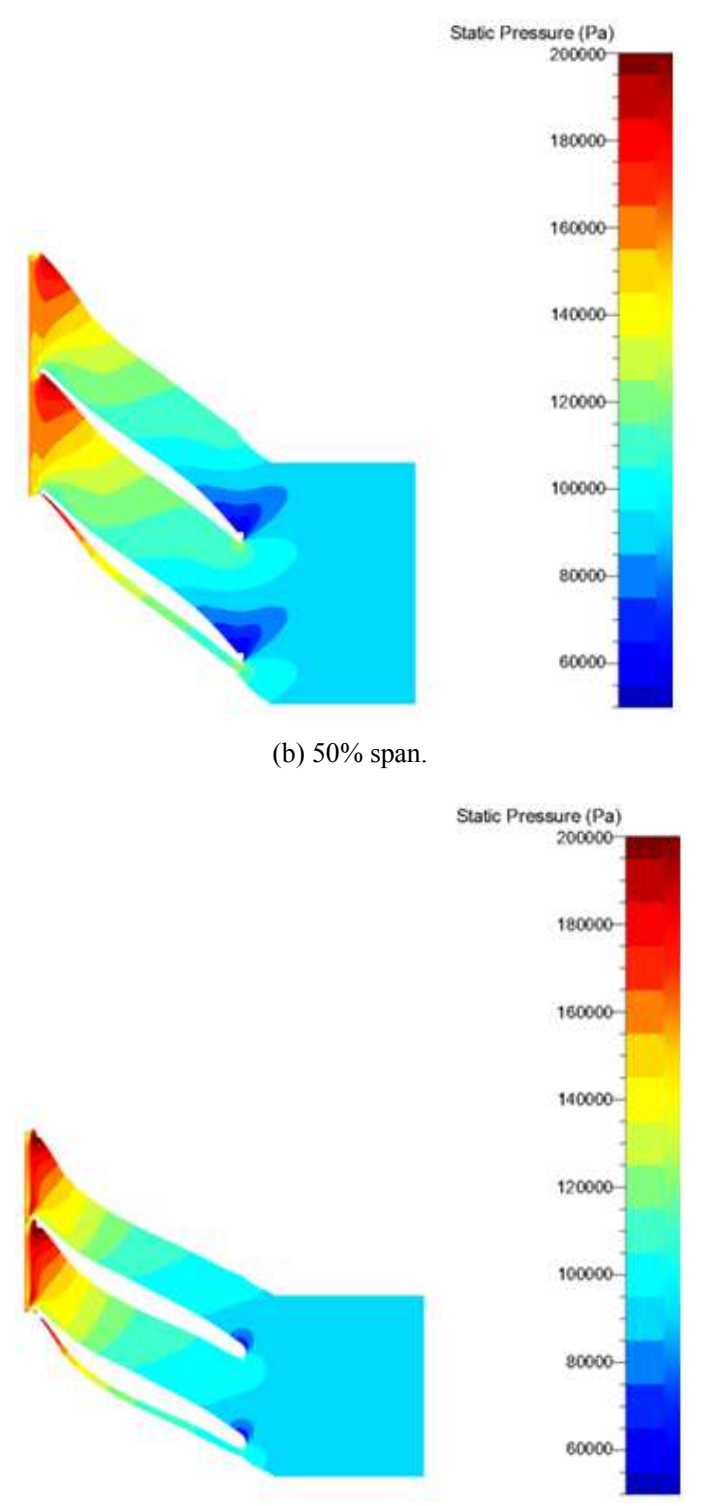

(b) $50 \%$ span.

(c) $10 \%$ span.

Figure 6. Design1 static pressure contour.

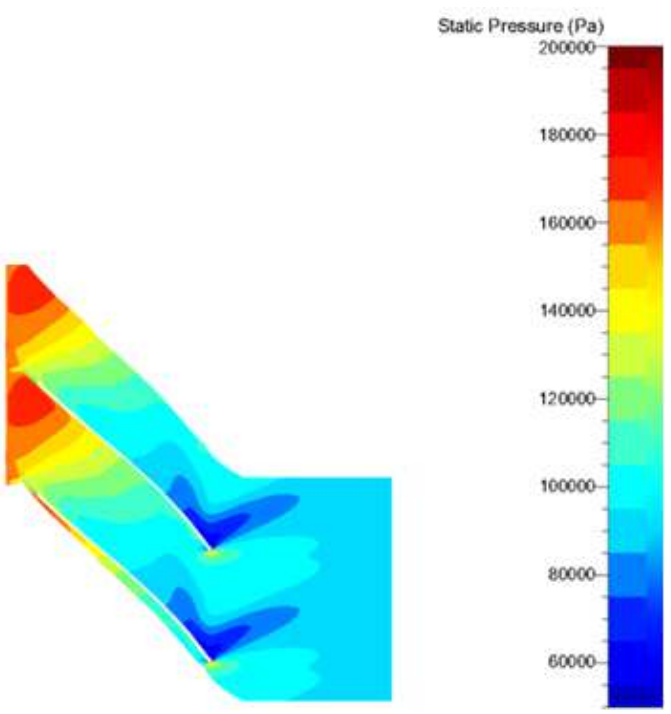

(a) $90 \%$ span. 

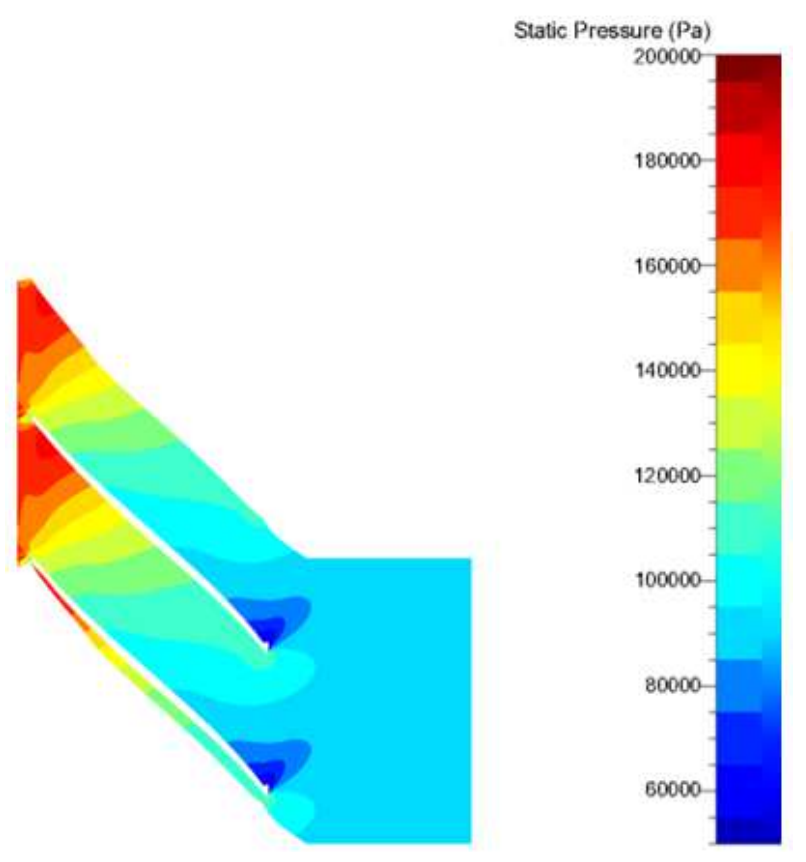

(b) $50 \%$ span.
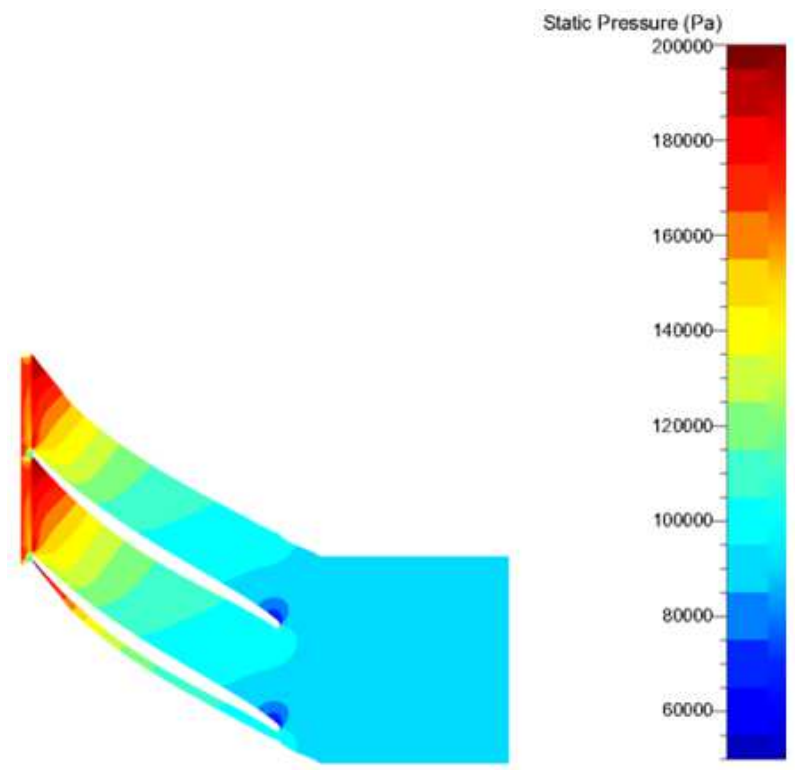

(c) $10 \%$ span.

Figure 7. Design2 static pressure contour.

As can be seen from Figure 8, the constant static pressure lines is more inclined to the normal direction of the shroud and hub lines from Design2 to the outlet of Design2. The secondary flow loss is correspondingly reduced, which is beneficial to the performance of the wheel.

Figure 9 is the static pressure distribution intercepted from the vaneless diffuser section at the average meridian exit of the wheel. It can be seen that the static pressure variation of Design2 along the span direction of the diffuser is controlled within 330Pa, while Design1 is expanding along the expansion. The static pressure change the amplitude of the span direction of the pressure device is controlled within the range of $800 \mathrm{~Pa}$. The static pressure distribution at the outlet of Design2 is obviously more uniform than that of Design1.

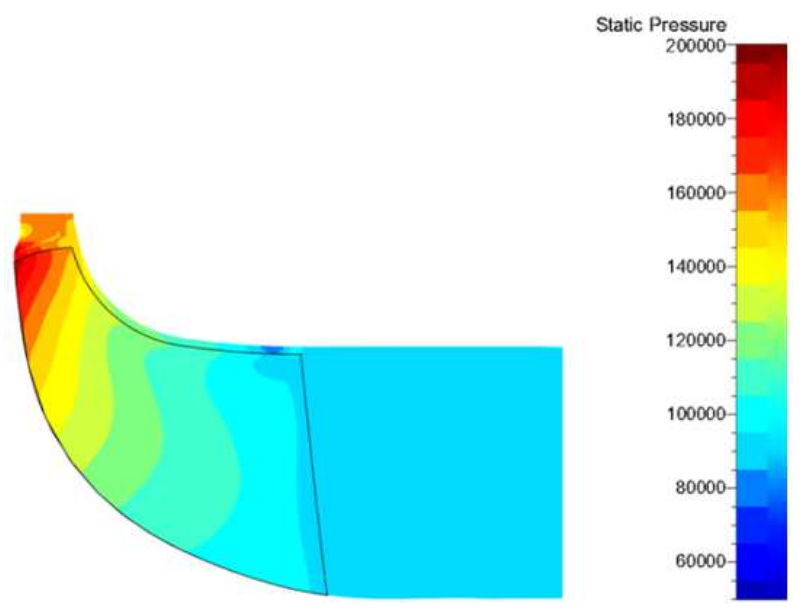

(a) Design 1.

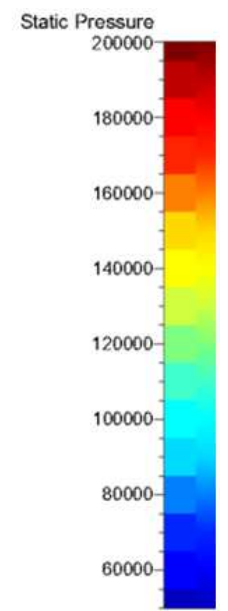

(b) Design 2.

Figure 8. Static pressure distribution of mean meridian.

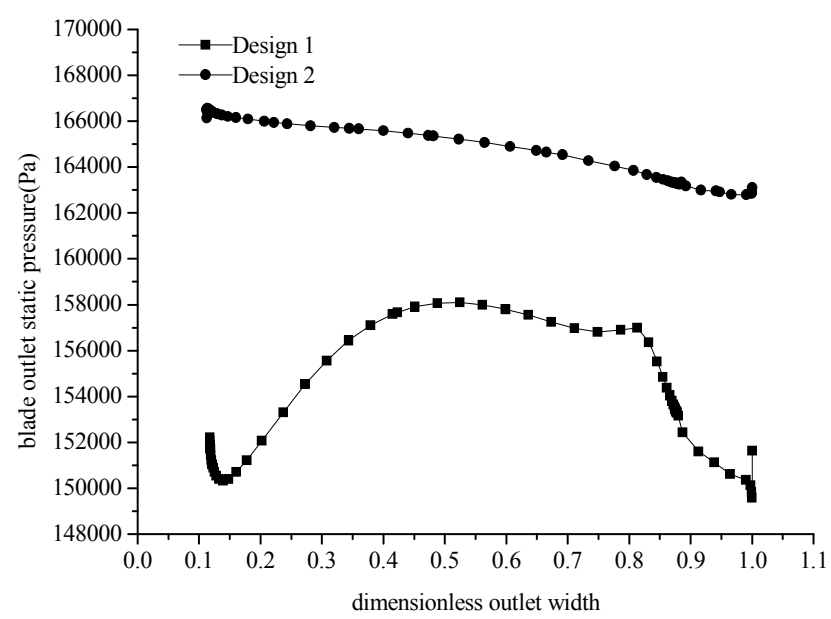

Figure 9. Static pressure distribution in the span direction of the wheel's average meridian exit (Red is Design2).

As can be seen from Figure 10 that Design2 redistributes the load of the blade in the span direction, especially after the wheel exit adopts a reasonable arc design. It places more load 
in the middle $20 \%-80 \%$ moving average area of the blade. Reasonably reduce the tip load, so that the tip gap leakage loss is correspondingly reduced.
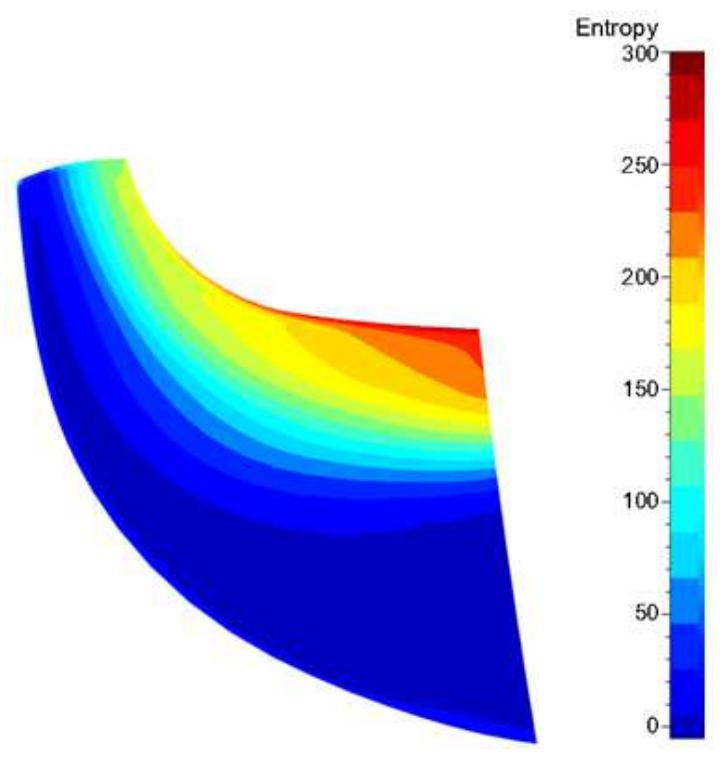

(a) Design 1.
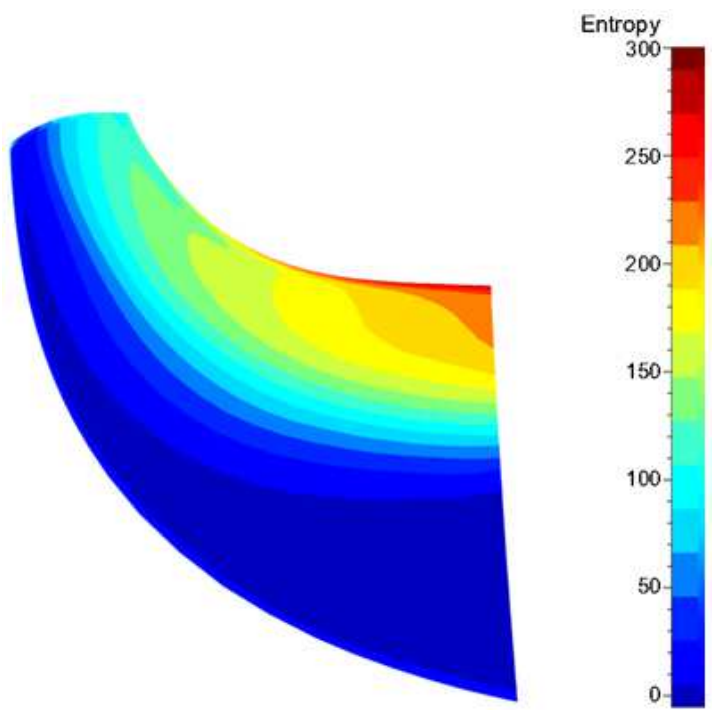

(b) Design 2.

Figure 10. Comparison of mean meridional surface entropy.

As can be seen from Figure 11 below, the static pressure distribution at the outlet of the Design2 wheel is more uniform. Nearly $4 / 5$ of the static pressure in the circumferential direction is stable within $150,000 \sim 180,000$ $\mathrm{Pa}$. The uniform static pressure distribution is conducive to the performance of the wheel and also improves downstream pressure. The performance of the rotor assembly is also beneficial to the improvement of the surge ability of the wheel.

From the distribution of the absolute Mach number of the wheel exit in Figure 12, it can be seen that the Design1 wheel has a low Mach number area on the shroud side, and a local low Mach number area also appears on the hub. The minimum Mach number area is also larger than Design2, indicating that more work is performed on the fluid under a high backpressure gradient by using Design2, which improves the speed of the low-energy fluid and improves the efficiency and steady-state flow range.

As can be seen from the absolute total pressure at the exit of the wheel in Figure 13, Design1 has a large area of low pressure area on the suction side of the wheel, which indicates that the gas loss there has increased, and the gas energy has dissipated, resulting in a decrease in the gas total pressure.

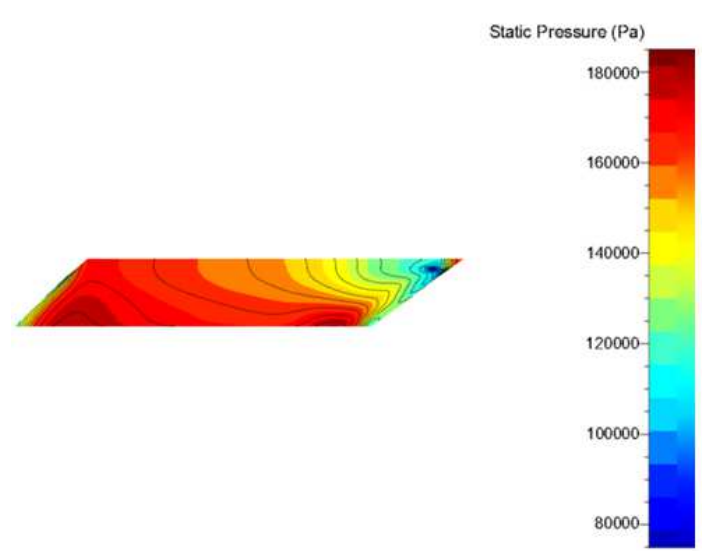

(a) Design 1.

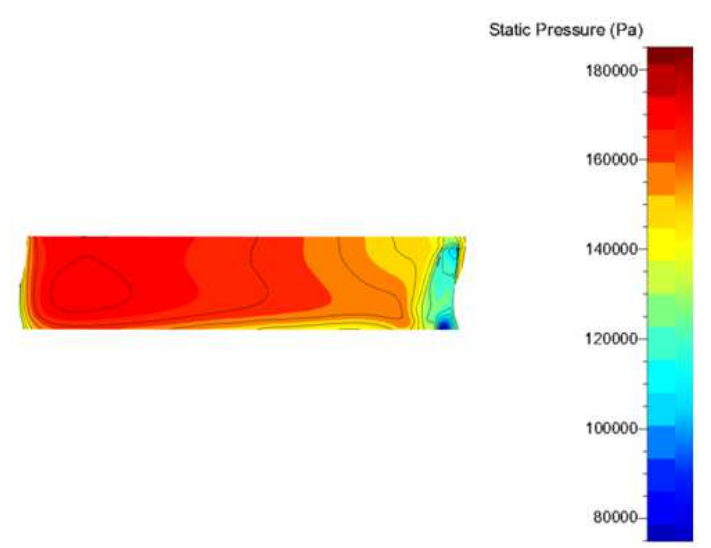

(b) Design 2.

Figure 11. Static pressure distribution at the wheel outlet.

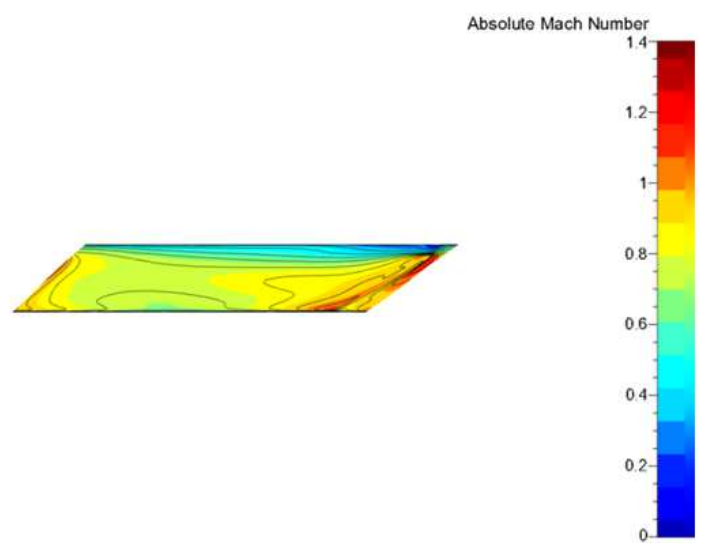

(a) Design 1. 


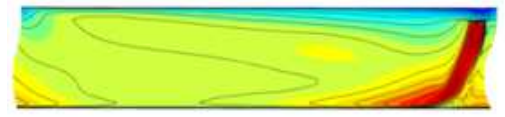

Absolute Mach Number

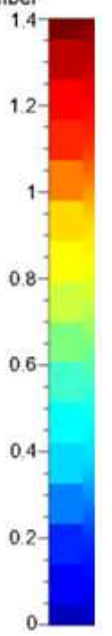

(b) Design 2.

Figure 12. Absolute Mach number distribution at wheel exit.

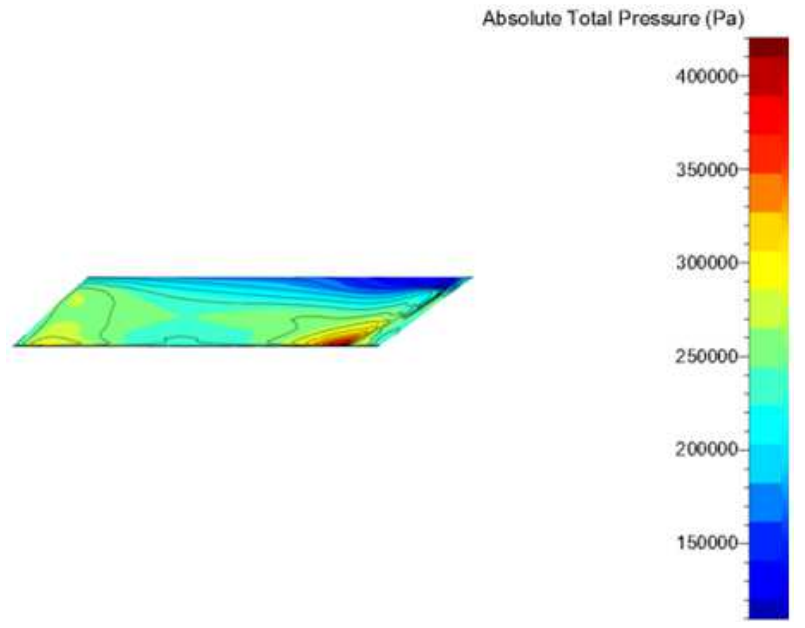

(a) Design 1.

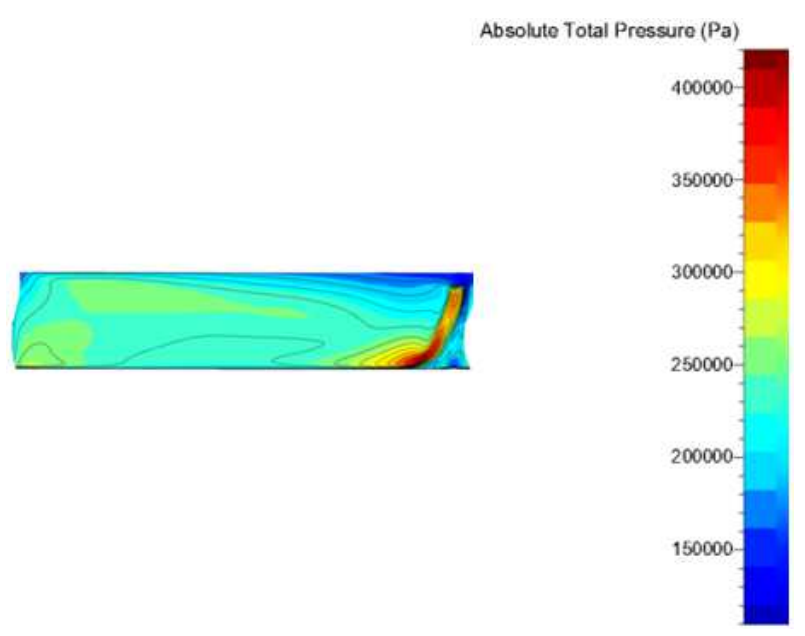

(b) Design 2.

Figure 13. Absolute total pressure distribution at the wheel outlet.

\section{Conclusions}

A high efficient wide operation range gasoline turbocharger centrifugal compressor was developed to meet the customers' needs. The CFD analysis, gas stand and onengine tests all demonstrated that the current compressor had better performance than original compressor. The gas stand and on-engine tests were agreed with CFD. It was demonstrated that the CFD can be used to predicated the compressor performance and also can be a design tool. This research was also demonstrated that the meridional shape of the impeller can be optimized to have better compressor performance. The study was also demonstrated that the design process could design the compressor in a fast way to meet the customers' needs. The current design process is inhouse compressor design bench mark and will be used for future compressor developments.

\section{References}

[1] H. P. Dickmann, T. S. Wimmel, J. Szwedowicz, D. Filsinger, C. H. Roduner, Unsteady flow in a turbocharger centrifugal compressor, three-dimensional computational fluid dynamics simulation and numerical and experimental analysis of impellre blade vibration. Journal of turbomachinery 128 (3), 455-465 (2006).

[2] C. Xu and R. S. Amano, Computational Analysis of Scroll Tongue Shape to Compressor Performance by Using Different Turbulence Models, International Journal for Computational Methods in Engineering Science and Mechanics, Vol. 11 No. 2, 85-99, 2010.

[3] C. Xu, Design Experience and considerations for centrifugal compressor development, Journal of aerospace engineering 221 (2007) 273-287. Proceedings of the institution of Mechanical Engineers, Part G: Journal of Aerospace Engineering, 221 (2), pp 273-287.

[4] C. Xu, R. S. Amano, Development of a Low Flow Coefficient Single Stage Centrifugal Compressor, International Journal for Computational Methods in Engineering Science and Mechanics, 10 (2009) 282-289.

[5] C. Xu, L. Chen, and RS Amano, Design System Development for a Fuel Cell Centrifugal Compressor, International Journal of fluid mechanics and thermal sciences, 2019; 5 (4): 96-101, doi: $10.11648 /$ j.ijfmts.20190504.12.

[6] C. Xu, R. S. Amano, On the Development of Turbomachine Blade Aerodynamic Design System, International Journal for Computational Methods in Engineering Science and Mech, 10 (3) (2009), pp. 186-196, $10.1080 / 15502280902795052$.

[7] C. Xu, R. S. Amano, Computational Analysis of Swept Compressor Rotor Blades," International Journal for Computational Methods in Engineering Science and Mechanics, 9 (6), 374-382, (2008), 10.1080/15502280802365840.

[8] C. Xu, R. S. Amano, Effects of Asymmetric Radial Clearance on Performance of a Centrifugal Compressor, ASME, Journal of Energy Resources Technology 140 (5), (2017), DOI: $10.1115 / 1.4038387$.

[9] C. Xu, R. S. Amano, Centrifugal Compressor Performance Improvements Through Impeller Splitter Location, J. Energy Resour. Technol. 140 (5), (2017), doi: 10.1115/1.4037813. 
[10] T. Ghisu, G. T. Parks, J. P. Jarrett, and P. J. Clarkson, “An integrated system for the aerodynamic design of compression systems-part II: application," Journal of Turbomachinery, vol. 133, no. 1, Article ID 011012, 8 pages, 2011.

[11] T. Verstraete, Z. Alsalihi, and R. A. Van den, "Multidisciplinary optimization of a radial compressor for microgas turbine applications," Journal of Turbomachinery, vol. 132, no. 3, 7 pages, 2010 .

[12] J. Gonzalez, J. Fernandez, E. Blanco, and C. Santolaria, Numerical Simulation of Dynamic Effects Due to ImpellerVolute Interaction in a Centrifugal Pump, ASME J. Fluids Eng., 124, (2002), 10.1115/1.1457452.

[13] C. Xu, R. S. Amano, Aerodynamic and structure considerations in centrifugal compressor design-blade lean effects, GT2012-68027 (2012).

[14] ANSYS Inc., Ansys version 15, ANSYS, Inc, 275 Technology Drive, Canonsburg, PA 15317, (2013).

[15] C. Xu, R. S. Amano, Empirical Design Considerations for Industrial Centrifugal Compressors, International Journal of Rotating Machinery, 2012 (2012) 1-16.

[16] C. Xu, R. S., Development of a Low Flow Coefficient Single Stage Centrifugal Compressor, International Journal for Computational Methods in Engineering Science and Mechanics, 10 (2009) 282-289.

[17] C. Xu, R. S. Amano, The Development of a Centrifugal Compressor Impeller, International Journal for Computational Methods in Engineering Science and Mechanics, 10 (2009) 290-301.

[18] C. Xu, R. S. Amano, Study of the flow in a centrifugal compressor, Int. J. of Fluid Machinery and System, 3 (3) (2010), pp. 260-270, 2010.3.3.260.

[19] R. V. Chima, A three-dimensional unsteady CFD model of compressor stability, ASME Turbo Expo 2006, Power for Land, Sea, and Air, pp. 1157-1168. American Society of Mechanical Engineers (2006).

[20] J. Denton, W. Dawes, Computational fluid dynamics for turbomachinery design, Proceedings of the Institution of Mechanical Engineers, Part C: Journal of Mechanical Engineering Science 213 (2), 107-124 (1998).
[21] M. G. Turner, A. Merchant, D. Bruna, A Turbomachinery Design Tool for Teaching Concepts for Axial-Flow fans, compressor, and Turbines, GT2006-90105, May 8-11, 2006, Barcelona, Spain.

[22] C. $\mathrm{Xu}$ and R. S. Amano, "On the Development of Turbomachine Blade Aerodynamic Design System,' International Journal for Computational Methods in Engineering Science and Mech, Vol. 10, No. 3, pp. 186-196. 2009. https://doi.org/10.1080/15502280902795052.

[23] C. Xu, H. Q, Yang, and Zhongwei YiThe development of an integrally geared centrifugal compressor, International Journal of fluid mechanics and thermal sciences, vol 3, 2019. doi 10.11648/j.ijfmts.20190501.11.

[24] Xin $\mathrm{Fu}$, Yingying $\mathrm{Xu}$, Yan Zhang, "Research on Flow Characteristics of Upstream Cavity with Labyrinth Seals in Axial Compressor" International Journal of fluid mechanics and thermal sciences, 2019; 5 (3): $82-90$ DOI: 10.11648/j.ijfmts.20190503.14.

[25] C. R. Weber and M. E. Koronowski, "Meanline performance prediction of volutes in Centrifugal compressors," in Proceedings of the ASME 31st Gas Turbine Conference and Exhibit, Dusseldorf, Germany, 1987. View at: Google Scholar.

[26] J. S. Arora, Introduction to Optimum Design, MCGraw-Hill, New York, NY, USA, 1998.

[27] D. Bonaiuti, A. Arnone, M. Ermini, and L. Baldassarre, "Analysis and Optimization of transonic centrifugal Compressor Impellers Using the Design of Experiments Technique," G T-2002-30619. View at: Google Scholar.

[28] M. J. Harry, The Nature of Six Sigma Quality, Motorola University Press, Shaumburg, Ill, USA, 1997.

[29] C. Xu and R. S. Amano, "A hybrid numerical procedure for cascade flow analysis," Numerical Heat Transfer, Part B, vol. 37, no. 2, pp. 141-164, 2000. View at: Google Scholar.

[30] C. Xu and R. S. Amano, "Computational analysis of pitchwidth effects on the secondary flows of turbine blades," Computational Mechanics, vol. 34, no. 2, pp. 111-120, 2004. 